\title{
PARAPLEGIA IN A PATIENT WITH EPIDURAL CATHETER
}

\author{
CARDOSO C. ${ }^{1}$, REgo J. ${ }^{1}$, GOMES A. ${ }^{1}$, CARDOSO H. ${ }^{1}$
}

${ }^{1}$ Anesthesiology Department, Centro Hospitalar Tâmega e Sousa - Penafiel, Portugal

\section{INTRODUCTION}

Paraplegia due to spinal cord infarction is a rare and devastating perioperative event. Its occurrence in the setting of epidural technique is even rarer. Among the possible causes some are potentially treatable but need high suspicion index and immediate action. [1]

\section{CASE REPORT}

- Male, 61 years-old, scheduled for voluminous abdominal hernia repair.

- Hypertension, type II diabetes, obesity, surgical ressection of rectum cancer 9 years before with neoadjuvant CRT.
- ASA III
- General anesthesia combined with a lumbar continuous epidural infusion.
- Epidural catheter on L1 - L2 space, single prick.

RECOVERY

ROOM

\section{NEUROLOGY CONSULTATION}

0 $2 h$ $4 h$ $24 h$ $26 h$ $32 h$

Hemodynamically stable

* Continuous epidural infusion of Ropivacaine 0,375\%
Ropivacaine

$0,2 \%$ + Morfine $0,005 \%(6 \mathrm{~mL} / \mathrm{h})$

* No Motor deficits

* No Pain
Autonomously walked

* Paraplegia of Lower limbs
Hypoesthesia

* No reflexes

* Sphincters dysfunction

- Unaffected

proprioception $34 h$ $48 h$

CT MRI
* "Conus medullaris" ischaemia

\section{DISCUSSION}

The epidural technique is relevant in this clinical scenario because it could have been the cause of the neurological syndrome or a confounder, delaying the diagnosis. The ethiopathogenesis of medullar infarction is multifactorial and complex. The cardiovascular risk factors, post-radiation vasculitis and prothrombotic state (surgery and malignancy) have been described as contributors for medullar infarction and ischaemia.[2]

Since the patient was able to walk the morning after while running the epidural, added to the sudden onset of the paralysis, we can arguably exclude the epidural tecnique as the main cause of neurological deficits.

\section{CONCLUSION}

The rarity of this complication justifies the publication of the case because it draws the attention for the possible occurrence of neurologic impairment in patients undergoing neuraxial techniques while not being directly causative.

[1] T. M. Cook, D. Counsell, J. A. Wildsmith, and Project Royal College of Anaesthetists Third National Audit, 'Major Complications of Central Neuraxial Block: Report on the Third National Audit Project of the Royal College of Anaesthetists', Br J Anaesth, 102 (2009), 179-90. [2] I. A. Hobai, E. A. Bittner, and

L. Grecu, 'Perioperative Spinal Cord Infarction in Nonaortic Surgery: Report of Three Cases and Review of the Literature', J Clin Anesth, 20 (2008), $307-12$ 